\title{
Characteristic Features of Male Germline Development in Primates
}

\author{
Rüdiger Behr \\ Platform Degenerative Diseases, German Primate Center - Leibniz Institute for Primate Research, and DZHK (German Center for \\ Cardiovascular Research), Göttingen, Germany
}

\begin{abstract}
The germline is constituted by all cells that have the potential to transmit their genetic information to the next generation. The germline can be considered as a defined sequence of genetic, cellular, and developmental processes recurring in each generation in order to ensure the continuity of a species-specific reproduction program. Although basic mechanisms of germline development in mammals are highly conserved, relatively slight yet relevant modifications of germline development evolved in different groups of mammals to adapt the entire process to the specific requirements of and conditions in each species. This review highlights selected aspects that illustrate germline adaptations and characteristics in primates mainly in comparison to the mouse, which is the best investigated mammalian model organism in reproductive biology.

C 2017 The Authors

Published by S. Karger AG, Basel
\end{abstract}

The germline is constituted by all cells that have the potential to submit their genetic information to the next generation. The cycle of the germline in mammals is characterized by the recurring sequence of (1) fertilization, i.e., fusion of 2 haploid gametes, resulting in (2) a diploid phase of early embryonic development, which leads to (3) the specification and separation of germ cells (primordial germ cells; PGCs) from somatic cells, followed by (4) several rounds of mitotic divisions of the germ cells. Then (5) the germ cells enter meiosis, i.e., the genetic reduction division, resulting in (6) haploid cells forming gametes again. Fusion of the haploid male and the female gametes completes the cycle of the germline and begins the next generation (Fig. 1). This sequence of events occurs in all mammals. However, different species exhibit specific adaptations and characteristics of 1 or more phases of the cycle of the germline. Remarkably, the cycle of the germline is an extremely robust process that works "endlessly". On the other hand, certain dynamics of the germline is essential for evolution since only modifications of the germline cells can lead to (genetically or epigenetically) inherited traits possibly resulting in better-adapted offspring and, hence, supporting species diversion. In light of these conflicting goals, namely germline stability and genome dynamics, some selected characteristic features of male germ cell development in pri- 


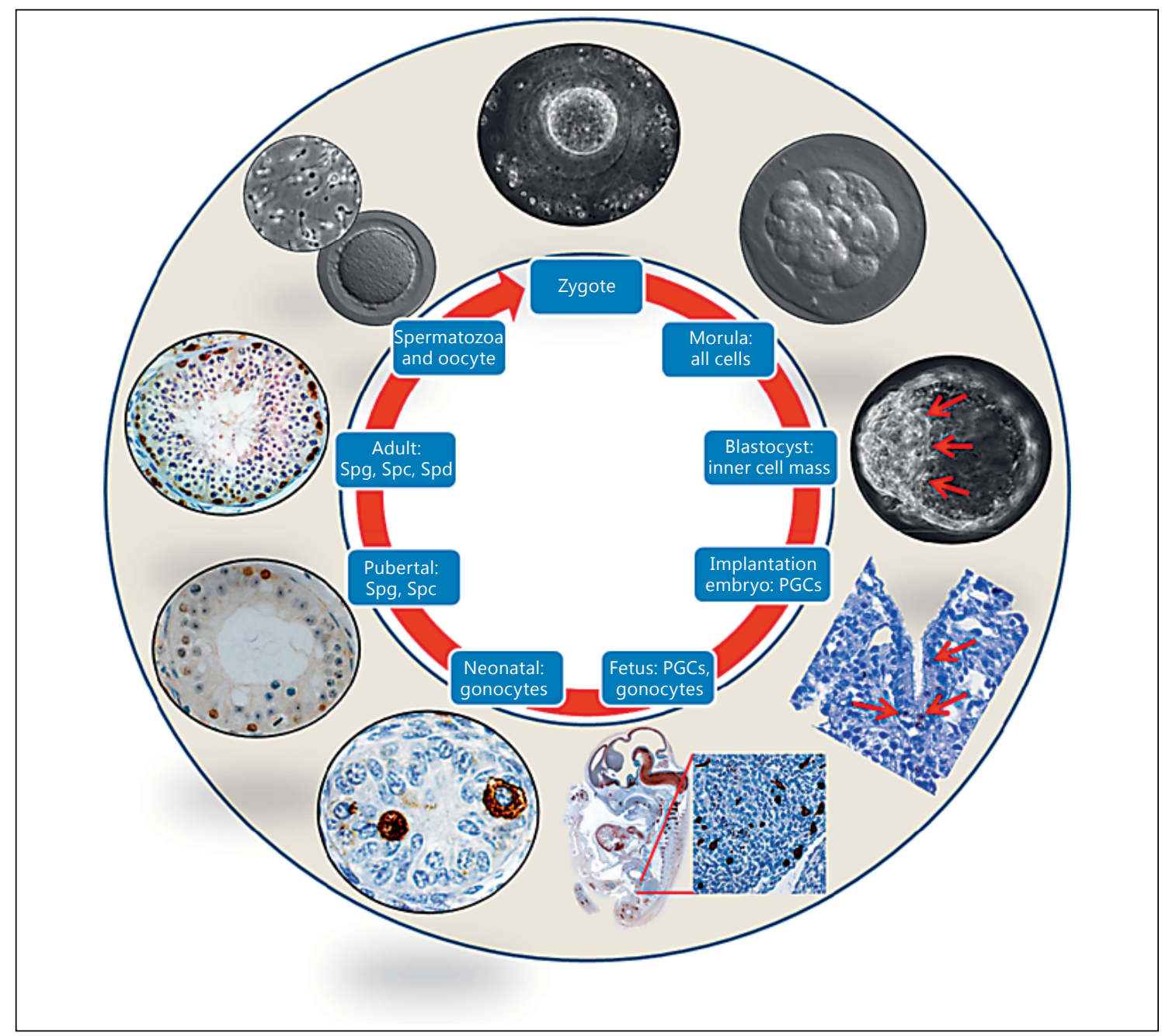

Fig. 1. Illustration of the cycle of the germline. All cells that have the potential to transmit their genetic information to the next generation belong to the germline. Germline cells are mentioned in the blue boxes. A new generation is initiated by the formation of a zygote, i.e., the fertilized oocyte. In the morula-stage embryo, the individual cells (blastomeres) are not yet specified. They are all potential progenitor cells of the prospective germ cells. The blastocyst consists of 2 clearly distinguishable cell populations: the inner cell mass cells (highlighted by red arrows) and the outer cell layer, i.e., the trophoblast. The germ cells develop from the inner cell mass cells. In the implantation embryo the first specified germ cells, called PGCs, occur. In the somite-stage embryos they are frequently located in the epithelium of the developing hind gut (red arrows). In the fetus, most PGCs have entered the forming gonad. The magnified area shows the distribution of germ cells in the gonadal primordium. In the neonatal testis the germ cells are mostly gonocytes, which are premeiotic germ cells located mostly in the center of the developing seminiferous tubule. At that stage, the tubule has no lumen. The gonocytes were stained using immunohistochemistry. In the pubertal testis, the seminiferous tubules form a lumen, and spermatogonia (Spg; stained brown) start to proliferate, giving rise to meiotic spermatocytes (Spc). In the adult testis, there are premeiotic Spg, meiotic Spc, and postmeiotic spermatids (Spd). Undifferentiated spermatogonia were stained by immunohistochemistry. Elongated spermatids are positioned on the apical (adluminal) surface of the germinal epithelium. Spermatozoa and oocytes are the gametes released from sexually mature male and female gonads, respectively. Fusion of the gametes initiates the next cycle of the germline. The different stages are illustrated using micro images (which are not shown to scale) of the Platform Degenerative Diseases of the DPZ. 
mates will be discussed in this chapter in comparison with the best-characterized mammalian species, the mouse (Mus musculus). The major focus will be on genetic, cellular, and developmental aspects. The term primate includes non-human primates (NHP) and humans, since both belong to the taxonomical (biological) order of primates.

\section{The Totipotent and Pluripotent Stages of the Germline}

After fertilization in mammals, the cells of the embryo are first totipotent and after only very few cell divisions their differentiation potential is restricted to pluripotency. A cell is totipotent if it can form a whole organism. In contrast, pluripotency is the ability of a cell to differentiate into all cell types of the body, but pluripotent cells lack the potential to form a whole organism. Both totipotent as well as pluripotent cells belong to the germline, and both states require a finely tuned temporal and spatial control $[1,2]$. Interestingly, the molecular regulation of pluripotency and the signal transduction pathways associated with this developmental state are not fully conserved in different mammalian species as has been shown for pluripotent cells of human and mouse origin $[3,4]$. Recently, marmoset monkey and mouse pluripotent cells directly isolated from embryos were also compared [5]. Some factors that have important roles in the mouse system [6, 7], like KLF2 and NROB1 (also known as $D A X-1$ ), were also highly expressed in the mouse preimplantation embryo [5] but were basically undetectable in the marmoset monkey (Callithrix jacchus) preimplantation embryo [5]. Also, the pluripotency-associated gene FBX015, although not essential for mouse development and fertility [8], shows dramatic differences in the expression levels in mouse and monkey preimplantation embryos. These selected examples highlight molecular differences in the regulation of pluripotency and, thereby, also differences in the maintenance of the germline at the mouse and primate preimplantation embryo stage. When the expression of components of specific signal transduction pathways was analyzed, many of them were found to be present in both species. However, transcripts encoding components of the TGF- $\beta /$ NODAL, FGF, and WNT signaling pathways, all important for different early developmental processes in mammals [911], were differentially expressed [5], suggesting that the utilization of specific signal transduction pathways is different between mouse and primate preimplantation embryos. Recent groundbreaking studies on the cynomolgus monkey (Macaca fascicularis) postimplantation embryo also revealed clear differences between primate and mouse epiblast [12], which is the embryonic precursor tissue of the PGCs, and PGC specification between the cynomolgus monkey and the mouse [13]. These comparative approaches employing mouse and primate allowed differentiation between basic pathways involved in the regulation of pluripotency in mammals and those mechanisms that apparently exhibit evolutionary plasticity [14]. In summary, general features of the early phase of embryonic development are conserved. However, there are also clear differences between the mouse and the primate regarding the regulation of pluripotency in preimplantation and implantation embryos. At present, the phenotypic and particularly the functional consequences of these molecular findings can only be speculated on, since functional and gene deletion studies are very demanding and challenging in NHP.

\section{Embryonic Specification of Primordial Germ Cells in Primates and the Mouse}

In the mouse, about 45 PGCs can be detected around embryonic day (E) 7-7.25 by alkaline phosphatase staining $[15,16]$. Lawson and Hage 
[15] also showed through lineage tracing experiments that PGCs are not finally specified in the mouse before E6.5. However, around E6.25-6.5, marked expression of fragilis, a gene important for germ cell specification, was found in nascent PGCs, followed by expression of stella around E7 [17]; stella is germ cell specific. However, recent data may suggest that the activation of a germ cell-characteristic gene expression program may start before E7, possibly already around E3.5-4 [18]. Hence, in the mouse there is a period of currently unknown length during which cells of the implanted embryo have the competence to differentiate into germ cells. The final specification, however, apparently occurs only around or even shortly after E7. These early implantation stages are difficult to obtain from humans (for ethical and practical reasons) as well as from NHP. Nevertheless, very recent in vitro as well as in situ studies delineated this phase of primate germ cell specification. Instructive in vitro systems employing human pluripotent stem cells suggested significant differences between mouse and human germ cell specification [19-22]. In the mouse, it has been shown that the interplay of BLIMP1 (also known as PRDM1), PRDM14, and AP2 $\gamma$ (TFAP2C) initiates a unique cellular program resulting in the specification of PGCs [23]. These factors synergistically suppress the ongoing somatic differentiation and activate the reexpression of pluripotency- and germ cell-specific genes [23]. PRDM14 is essential for PGC specification in mice [24]. Contrastingly, the role of PRDM14 in human germ cell specification seems to be only minor since this gene was only minimally expressed in in vitro assays of germ cell development compared to the mouse [21]. Remarkably, Sasaki et al. [13] showed that cynomolgus monkey PCGs did express PRDM14 in the context of natural embryos. This discrepancy between monkey and human PRDM14 expression in PGCs may either represent a speciesspecific difference (human vs. cynomolgus monkey) or may reflect the different approaches of
PGC investigation, i.e., pluripotent stem cell based for human PGC development and natural embryo based for monkey PGC investigation. A clear difference between primate and mouse PGC specification is the role of SOX17. This transcription factor is a key regulator of human PGC specification [19] and acts upstream of BLIMP1. In the absence of SOX17, no germ celllike cells were obtained from pluripotent stem cells, highlighting the role of SOX17 in human germ line specification [19]. Importantly, SOX17 has also been shown to be highly expressed, together with TFAP2C, in cynomolgus monkey PGCs [13]. In striking contrast, SOX17 has no apparent role during germ cell specification in mice [19]. In general, the pluripotent stem cellbased system for the (functional) investigation of primate PGC development appears to be a very useful alternative for potential in vivo studies in NHP for the following reasons. First, Sasaki et al. [22] compared the gene expression signatures of their in vitro-derived PGC-like cells with those of PGCs isolated from monkey embryos and found significant matching of both gene signatures, nicely validating the in vitro data. Second, SOX2 is a core pluripotency transcription factor expressed by mouse PGCs, and it is essential for mouse PGC development in vivo [25]. In striking contrast to the mouse, human PGCs neither express SOX2 during in vivo development, nor upon in vitro culture [26], while OCT4 and Nanog as additional core pluripotency factors [27] are expressed [28]. This pattern was recently confirmed by Sasaki et al. [13] for cynomolgus monkey PGCs and in our lab for marmoset monkey PGCs [29; unpubl. data], suggesting that a lack of SOX2 expression is a common characteristic of primate PGCs. Importantly, SOX2 was expressed in human pluripotent stem cells, but was undetectable or strongly repressed in human PGC-like cells derived from pluripotent stem cells $[19,30]$, which nicely recapitulates the dynamics of SOX2 expression during human and cynomolgus monkey PGC 
development in vivo. In summary, molecular players essential for mouse PGC development like SOX2 appear to have only minor or even no role in primate PGC formation. In contrast, SOX17 is essential for human PGC formation, but not in the mouse. These examples highlight clear differences in the molecular regulation of PGC specification and development between primates and the mouse.

\section{The Role of the Amnion and the Extraembryonic Ectoderm}

The extraembryonic ectoderm (ExE) plays an important role during mouse PGC specification [23]. PGCs respond to BMP4, which is secreted from the ExE during embryonic days E6.5-7.5 [31]. Mouse embryos lacking BMP4 fail to develop PGCs; they do not contain any germ cells [32]. These data suggest that the ExE is essential for proper PGC specification and development in the mouse. However, since the anatomy and morphology of the mouse and the primate embryo are fundamentally different, with a flat germ disc in primates and an egg cylinder in the mouse $[4,33]$, there is no direct structural counterpart of the mouse ExE in the primate embryo [34]. Recently, it was shown that the nascent (pregastrulation) amnion is the origin of PGCs in the cynomolgus monkey [13]. Giving rise to PGCs appears to be a unique function of the amnion in primates [13]. Furthermore, this study also provided insights into (potential) inductive processes regulating PGC specification and determination in primates. The amnion itself as the PGCgenerating tissue produces BMP4 and WNT3A, to which the PGCs may respond [13]. In summary, the significant anatomical differences between mouse and primate embryos at the time of PGC specification [4] and the amnion as the origin of primate PGCs [13] demonstrate significant species-specific adaptations in primates compared to the mouse.

\section{Gonocytes and Spermatogonial Stem Cells}

PGC specification and their initial development occur outside the gonads and even outside the embryo proper. In order to constitute a functional gonad, the PGCs have to be translocated from their extraembryonic position into the developing gonad, which is free of germ cells during the first steps of its differentiation. Only little is known about the primate (-specific aspects of) PGC migration and translocation [26, 29, 35-38]. Upon arrival in the male gonad, postmigratory PGCs are surrounded by cells forming the somatic parts of the developing testicular cords, which eventually become the seminiferous tubules in the adult testis. Upon inclusion in the testicular cords, the PGCs are called gonocytes. The gonocyte stage developmentally links the PGC stage with the spermatogonial stage and involves phases of relative quiescence, proliferation, migration from a central position within the testicular cord to the basement membrane of the developing germinal epithelium, and finally differentiation to a spermatogonial stem cell $[39,40]$. However, in mice, a subpopulation of gonocytes directly initiates spermatogenesis in order to fuel the first wave of sperm production without passing through an undifferentiated spermatogonial stage [41]. Again, only little is known about the molecular regulation of the development of gonocytes in primates [40, 42-45]. However, one aspect is evident: in primates there is an extended phase of relative quiescence of the gonocytes between the beginning of the gonocyte stage and the initiation of puberty, i.e., spermatogonia start to proliferate in order to initiate spermatogenesis. Although it has been shown that there is some germ cell proliferation and differentiation during the prepubertal period in the monkey [46] and in the human $[47,48]$ testis, this prepubertal period of relative testicular quiescence has no direct counterpart in rodents. In fact, a comparative analysis of the germ cell population in the neoand postnatal human, marmoset, and rat testis 
showed that GC differentiation and loss of pluripotency marker expression in marmosets is remarkably similar to that in the human but fundamentally different from the situation in rats [40]. Based on their findings, McKinnell et al. [40] concluded that researchers and clinicians need to be very cautious when extrapolating the results from rodent studies into humans. In mice, no gonocytes were found on postnatal day 11 [46], and all germ cells had developed to spermatogonia or spermatocytes. The first haploid round spermatids were seen in postnatal day 21 mouse testes, and spermatogenesis was already completed by postnatal day 35 in the mouse [49]. This is in sharp contrast to the marmoset, which first produces sperm cells around 12 months after birth [50], and to the human testis, where puberty is usually initiated around the age of 11-13 years. Although some signals involved in the initiation and regulation of puberty have also been identified in NHP [51], there are still major gaps of knowledge in this field [52]. In general, an extended period of relative testicular quiescence before the initiation of the first meiotic wave occurs in primates, but not in rodents. These are relevant adaptations to the different reproductive strategies of primates as K-selected species with few offspring, long periods of gestation, long and intensive parental care, and a long period until the reproductive age is reached. In contrast, as r-selected species, rodents have high numbers of offspring, short periods of gestation, little parental care, and reach adulthood and sexual maturity early [53].

According to the classical model, ongoing spermatogenesis in rodents is fueled by spermatogonial stem cells, which are called A single $\left(A_{s}\right)$ spermatogonia [54]. These are individual cells that are believed to be the starting point of a new clone of differentiating germ cells. They are characterized by the expression of several marker proteins such as GFR $\alpha 1$ (the GDNF receptor), NGN3, PLZF [for a review, see 55], SALL4 [56], and LIN28 [57]. In primates, the different puta- tive stem cell types were classified and named after their morphological appearance: $A_{\text {dark }}$ are considered to represent reserve stem cells, and $A_{\text {pale }}$ spermatogonia are considered to represent active stem cells in terms of sperm production [for a review, see 55]. However, 10 years ago Ehmcke and Schlatt [58] proposed a model of spermatogonial self-renewal and differentiation that was based on the assumption that the primate spermatogonial population is more plastic than previously thought. Moreover, the relatively simple mouse model was also recently profoundly revised [59]. In fact, these novel data suggest that an extended heterogeneous population of spermatogonia forms a flexible and to a certain extent reversible pool of cells with stem cell characteristics on the one hand, and on the other hand differentiating characteristics. These important findings may lead to a revised model of spermatogonial self-renewal, expansion, and differentiation in mammals. However, even if the unexpected finding of plasticity of the spermatogonia population in the mouse testis applies to all mammals, there are significant differences between the mouse and the primate spermatogonial stem cell pool. Regarding marker expression, this is very obvious for LIN28 [44] (Fig. 2). While many mouse spermatogonia strongly express this important developmental and pluripotency-associated factor [60], it could be detected only in an extremely minor subpopulation of primate spermatogonia [44]. Also, NGN3, an important lineage-specifying transcription factor in the pancreas [61], is already expressed in mouse spermatogonia from the $A_{s}$ stage onwards, but is absent from rhesus monkey $A_{\text {dark }}$ and $A_{\text {pale }}$ stem spermatogonia [55]. Irrespective of the validity of the different models of spermatogonial self-renewal and differentiation, it appears that mouse spermatogonia are in a more primitive, gonocytelike state compared to primate spermatogonia. Single cell transcriptome analysis in combination with functional assays will further clarify the mode of the spermatogonial system in different 


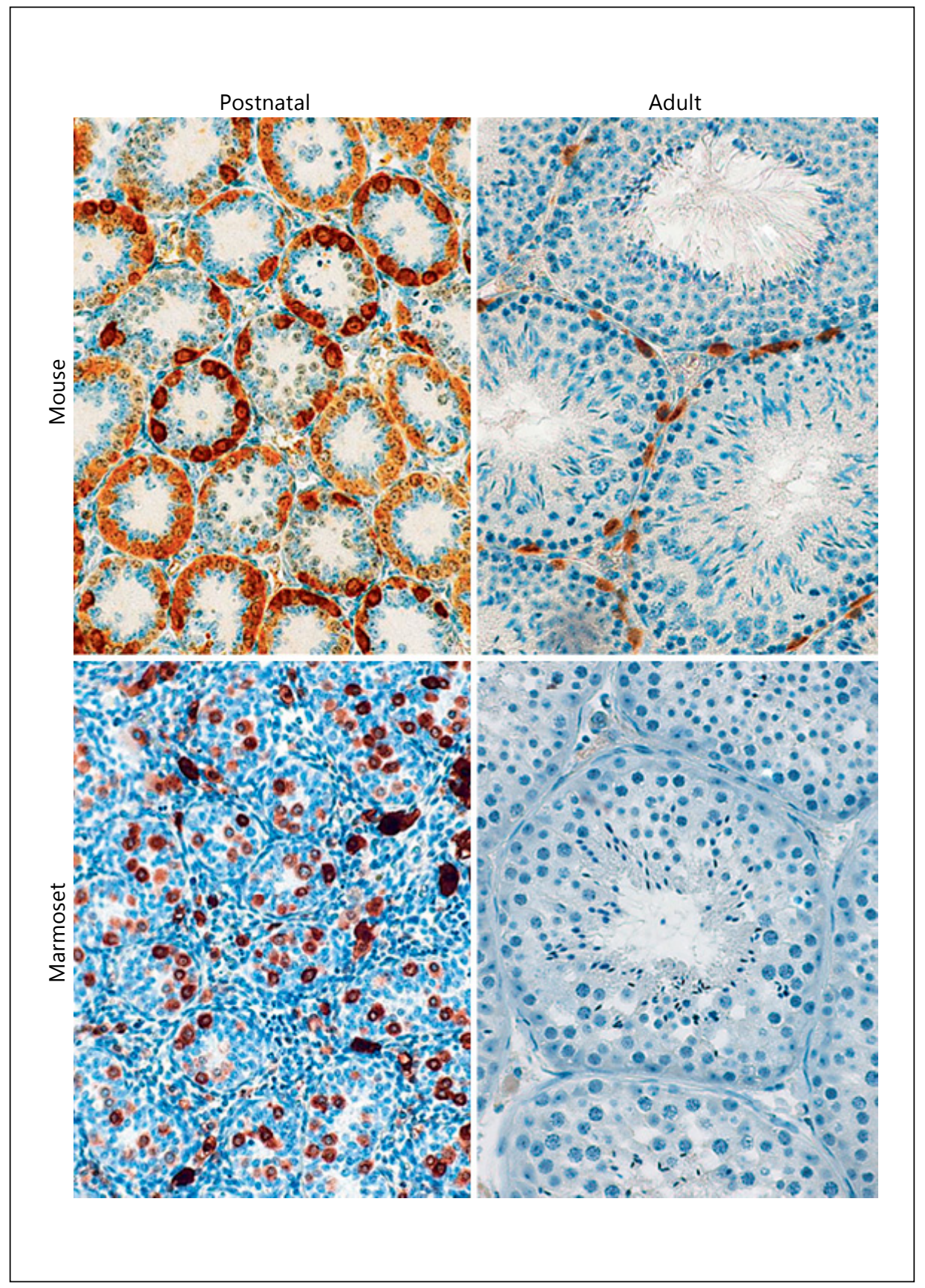

Fig. 2. Differential expression of the stem cell factor LIN28 in adult spermatogonia of marmoset monkey and mouse testes. In the immature postnatal testes, the gonocytes/spermatogonia are LIN28-positive in both species. In contrast, in the adult testes, only mouse spermatogonia are positive for LIN28, while the marmoset monkey spermatogonia (and those of all other NHP species tested so far) are generally negative for LIN28. Only very few primate spermatogonia express LIN28 [44]. 
mammals, including primates, within the next few years.

One highly significant and undoubted difference between premeiotic germ cell expansion in the mouse and primate testis, however, is the number of mitotic cell divisions before the spermatogonia eventually enter meiosis. While there are 10 or 11 mitotic divisions of spermatogonia in the mouse before they enter meiosis, in primates there are significantly fewer premeiotic cell divisions: 5 in Rhesus monkeys and only 2 in humans (for a review, see Ehmcke and Schlatt [58]). This means that the size of the clones emerging from 1 stem cell is much bigger in the mouse than in the human. The rhesus monkey clone size is between that of the mouse and the human. This difference in clone size in turn also implies that the density of stem cells in the primate testis is much higher than in the mouse testis. It was hypothesized that the germ cell clonal size (which is inversely correlated with the stem cell density) determines whether a primate species predominantly exhibits a single- or a multistage organization of the cross-section of the germinal epithelium [62]. The human testis shows a multistage system in around $80 \%$ of all seminiferous tubule cross-sections [62], which corresponds to the small germ cell clone size in the human testis [63]. Similarly, the marmoset monkey also predominantly shows a multistage organization, with up to 5 stages per cross-section $[62,64]$. This high number of stages per cross-section suggests a very small clone size and very few premeiotic mitotic divisions of spermatogonia in this species. In contrast, the macaque species showed a multistage organization of the germinal epithelium cross-section in only $20-33 \%$ of all cross-sections [62], correlating well with the larger number of premeiotic spermatogonial cell divisions [63]. Hence, in primates, the species-specific histological organization of the seminiferous epithelium most likely evolved depending on the number of premeiotic spermatogonial cell divisions. The fact that both the human and the marmoset exhibit a multistage system makes the marmoset monkey a very good model for human spermatogenesis [64]. Finally, when NHP are used as experimental animals in reproductive biology, it must be considered that some primate species, including the rhesus monkey, have seasonal testicular activity with a transient block of spermatogonial proliferation [65], while seasonality has never been described for the human and the marmoset testis.

\section{Spermatogonial Stem Cell Culture}

For more than 20 years, it has been possible to culture mouse spermatogonia [66]. Nagano et al. [66] demonstrated the spermatogonial stem cell identity of the cultured cells by transplantation into a recipient testis, where the cells repopulated the seminiferous tubule and initiated complete spermatogenesis. Since then, mouse spermatogonia have been cultured in many laboratories around the world. They were genetically manipulated in vitro and transplanted into appropriate recipients in order to generate genetically modified mice [67], and were converted to a pluripotent state resembling embryonic stem cells [68]. Furthermore, rodent in vitro spermatogenesis was intensely investigated and finally successful [69-73] even when initiated from cultured spermatogonial stem cell lines [74]. Altogether, the culture of mouse spermatogonial stem cells is well established. In the primate, it is still a matter of debate whether long-term culture and the expansion of spermatogonial stem cells, i.e., the culture of functional stem cells, is possible. While some studies could detect human $[75,76]$ and marmoset monkey $[77,78]$ spermatogonia only for very limited periods in culture, other reports described the long-term culture of human spermatogonia [79-82] and even their differentiation into haploid germ cells [83]. However, since some markers used in human long-term spermatogonial culture studies are not unequivocal germ cell markers, it remains a matter of conten- 
tion at present whether the cultured cells are really functional germ cells. The only functional test currently possible would be transplantation of long-term cultured NHP germ cells into a recipient testis of the same species and subsequent generation of offspring from the long-term cultured and transplanted germ cells. This is currently not possible in humans for ethical reasons due to the very limited knowledge about the safety of the procedure for the potential offspring. Nevertheless, in the long term, this procedure may be a promising strategy to preserve the prospective fertility of male prepubertal cancer survivors [84], and a very promising spermatogonial stem cell transplantation study has already been conducted in NHP with cryopreserved, but not long-term cultured spermatogonia [85]. In general, the long-term primate spermatogonial cell culture has to be improved. The robust spermatogonial stem cell culture in mice may reflect the more primitive developmental state of the mouse spermatogonial stem cells compared to the primate counterparts. In this context, it is tempting to speculate that the recently established concept of a naïve and a primed state of pluripotent stem cells [86] can also be translated to mouse (naïve) and primate (primed) spermatogonial stem cells.

\section{Considering Potential Limitations of Mouse Models of Human Male Infertility}

There exist excellent reviews on the genetic causes of male infertility $[87,88]$. Hundreds of mouse mutants exhibiting spermatogenic defects leading to infertility have been generated, illuminating the roles of many conserved mammalian fertility genes. However, although many of the mouse genes investigated in the context of infertility were also analyzed in infertile patients, only few mouse fertility genes were also found to be mutated in patients, like TEX11 [89]. Even if all mouse genes were to be mutated soon [90], it re- mains questionable whether these mice represent appropriate models of the majority of human infertile patients. This may be due to the following facts: (1) male infertility is a multifactorial disease, and the interplay of several factors in primates may be different from that in mice, (2) there might be significant epigenetic differences between mouse and primate germ cells, and (3) there are primate-specific genes that have no counterpart in the mouse genome. Importantly, the primate-specific transcripts are highly enriched in the brain and in the testis [91] (see also below). Therefore, it is likely that some aspects of male primate germ cell development as well as some cases of human infertility cannot be modeled in mice due to the absence of the relevant genes. In general, the aspect of the evolution of novel genes, particularly in the testis, has probably been underestimated until recently [92], except for the sex chromosomes [93-95].

\section{The Genome Perspective: Primate-Specific Genes and Mobile Elements}

In terms of the evolutionary perspective, genomes are highly dynamic, and several mechanisms for the birth of new genes have been identified [96]. While new protein-coding genes usually evolve from preexisting protein-coding genes, recently even "motherless" new proteincoding genes, which probably developed de novo from ancestral noncoding DNAs, were described in the human and ape genome [97]. Hence, during evolution, genome dynamics resulted in highly diverse genomes. Importantly, it was recently estimated that the human genome encodes more than 300 human-specific genes and around 1,000 primate-specific genes [91]. Since the number of human genes is less than 20,000, more than $5 \%$ of all human genes are primate specific. These new genes are predominantly implicated in brain and testis development and function. Within the testis, most of the "male 
genes" appear to be expressed by germ cells [98], but not by the somatic compartment of the testis. Consequently, testicular transcriptomes are also different in different species [98], and, probably even more strikingly, gene expression levels evolve faster in primates than in rodents [99]. Furthermore, primates exhibit a faster accumulation of alternatively spliced transcripts than other mammalian orders [100]. On the molecular level, the global removal of repressive epigenetic marks and a permissive chromatin state during meiosis may boost gene expression in male germ cells. This molecular environment in germ cells most likely represents the delivery room for novel genes, and based on this, the "out-of-the-testis hypothesis" of gene/genome evolution was established [98]. To summarize: (1) testicular germ cells are most likely the hotbed of genomic evolution; (2) there are hundreds of primate-specific genes with enriched activity in the testis; (3) the testicular transcriptome is significantly different from those of other organs, and (4) interestingly, there is a primate-specific acceleration of transcriptome evolution.

Retrotransposons are mobile self-replicating genetic elements that can spread over the genome via an RNA intermediate [101] and can be considered to resemble retroviruses. However, viruses spread horizontally between organisms. In contrast, retrotransposons spread vertically through the germ line. Alu elements are a subclass of retrotransposons of about 300 base pairs in length. Since there is no specific defense or removal mechanism for Alu sequences, there is a steady accumulation of Alu sequences during evolution [101]. Importantly, Alu sequences are unique to primates, and they comprise around $11 \%$ of the human genome [102], while all transposable elements together constitute around 50\% of the human genome [103]. Alu germline activity is the highest of all human retrotransposons and significantly contributes to genome instability and, hence, genetic population diversity [101]. Furthermore, another family of retrotranspo- sons, the hominid-specific SINE-VNTR-Alus (called SVA), are the youngest of these elements, constituting $0.13 \%$ of the genome and originating approximately 25 million years ago [104]. The SVA are present in the human genome in about 3,000 copies. It has been shown that the elements of this family also contribute to the development of new genes in primates [104]. These examples highlight that significant parts of the primate genome are specific to primates and do not have any counterpart in the genomes of other mammalian taxa. Furthermore, these primatespecific portions of the genome are clearly not “junk DNA," but have functional relevance [105] - also in terms of primate-specific evolution [106].

\section{The Haploid Phase of the Germline}

Postmeiotic spermatids condense their chromatin in preparation for their release from the germinal epithelium and their subsequent passage through the female reproductive tract. Because of the block of transcription in spermatids [107] and the release of the residual body (a droplet of unnecessary cytoplasm also containing RNA), it was previously thought that sperm cells are free of RNA transcripts. Therefore, the transcriptome of the spermatids and sperm cells was not appreciated for a long time. This changed in recent years, and a very interesting study detected the highly surprising number of 16,900 different gene transcripts in spermatozoa [108]. This is more than in whole liver and in Sertoli cells, for instance [108]. Many spermatozoa transcripts may represent non- or incompletely destructed and retained transcripts from round and elongating spermatids. However, even if only a small fraction of the 16,900 transcripts encode functional RNAs, it becomes more and more evident that these transcripts (respectively, their corresponding genes) have evolutionary [109] and fertility-related [110] relevance. That species-spe- 
cific differences also occur in the spermatozoa transcriptome is nicely reflected by the fact that protamine expression is different in man and rat. While 2 protamines (protamine 1 and protamine 2) are expressed in human spermatozoa at a specific ratio (0.98 P1/P2 in normozoospermic men) [111], in rat spermatozoa protamine 2 transcripts are barely present, and the corresponding protein was not detected in rat spermatozoa [112]. Deviation from the $0.98 \mathrm{P} 1 / \mathrm{P} 2$ ratio in humans is a useful parameter to estimate a reduction of the fertilizing potential of human spermatozoa [111]. The importance of the tightly controlled P1/P2 ratio in human sperm samples, on the one hand, and the evolutionary plasticity of the protamine system in mammals, on the other hand, suggest that fertility-relevant haploid expressed genes are regulated in a human-specific way. Unfortunately, only very limited data are available on protamines in NHP [113], and, to the best of my knowledge, $\mathrm{P} 1 / \mathrm{P} 2$ ratios are yet to be determined in NHP.

\section{Conclusion and Outlook}

Primates and rodents differ in many relevant biological aspects, including neurobiology, life span, gestation period, and the number of progeny. This review highlights selected primate-specific features of germ line development, which are not as evident as other biological differences between primates and rodents, but which are probably not less significant with regard to reproduction, ontogenesis, and evolution. These include the differential regulation of developmental potency in the preimplantation embryo, the apparently different origins of PGCs in the primate and mouse postimplantation embryo, and the differential expression of some important (transcription) factors in primate and mouse premeiotic germ cells, namely SOX2, SOX17, and LIN28. Furthermore, the size and expansion of germ cell clones in the testis is regulated in a species-spe- cific way - also within the order of primates - resulting in typical patterns of tubular cross-sections (preferentially single-stage organization in human and marmoset monkey vs. preferentially multistage organization in the macaques). Mouse spermatogonial stem cell culture is well established. In contrast, it remains controversial whether human and NHP long-term spermatogonial stem cell culture and expansion has thus far been successful. Regardless, the fact that the mouse spermatogonial stem cell culture protocols were not applicable to human and NHP spermatogonial stem cells may reflect biological differences between rodent and primate spermatogonial stem cells. Moreover, it must always be considered that the primate genome significantly differs from the rodent genome; there are up to 1,000 primate-specific genes, and there are also primate-specific mobile genetic elements. Taking into account that the primate-specific genes are particularly active in germ cells, this genomic difference between primates and rodents cannot be overestimated in germ cell biology. Furthermore, it appears reasonable to assume that upcoming research will uncover many additional primate-specific factors and characteristics of germline development, particularly in light of high-throughput transcriptome and epigenome analyses of single cells and the emergence of genetically modified monkeys. Finally, with regard to the investigation of infertility in humans, it is on the one hand important to realize potential limitations of non-primate animal models for primate (including human) germ cell biology and fertility. On the other hand, human geneticists, andrologists, and reproductive biologists may be well advised to consider and investigate specific aspects of the primate germline as causes of human infertility in more detail. It therefore appears to be essential to further investigate the primate - including the human - germline and germ cell biology in order to obtain better insights into human reproductive function and failure. 


\section{Acknowledgements}

I highly appreciate the support by and fruitful discussions with many colleagues and friends. I would like to apologize to all colleagues whose great work could not be discussed in this review although so many excellent publications deserve acknowledgement. I thank Ker- stin Zaft and Ellen Wiese for their great and patient support.

The work performed in the author's lab was supported by institutional resources of the German Primate Center and by grants from the Deutsche Forschungsgemeinschaft (DFG) and the Bundesministerium für Bildung und Forschung (BMBF).

\section{References}

1 Zernicka-Goetz M, Morris SA, Bruce AW: Making a firm decision: multifaceted regulation of cell fate in the early mouse embryo. Nat Rev Genet 2009;10: 467-477.

2 Goolam M, Scialdone A, Graham SJ, Macaulay IC, Jedrusik A, Hupalowska A et al: Heterogeneity in Oct4 and Sox 2 targets biases cell fate in 4-cell mouse embryos. Cell 2016;165:61-74.

3 Davidson KC, Mason EA, Pera MF: The pluripotent state in mouse and human. Development 2015;142:3090-3099.

4 Rossant J: Mouse and human blastocystderived stem cells: vive les differences. Development 2015;142:9-12.

5 Boroviak T, Loos R, Lombard P, Okahara J, Behr R, Sasaki E, et al: Lineagespecific profiling delineates the emergence and progression of naive pluripotency in mammalian embryogenesis. Dev Cell 2015;35:366-382.

6 Wani MA, Means RT Jr, Lingrel JB: Loss of LKLF function results in embryonic lethality in mice. Transgenic Res 1998;7: 229-238.

7 Khalfallah O, Rouleau M, Barbry P, Bardoni B, Lalli E: Dax-1 knockdown in mouse embryonic stem cells induces loss of pluripotency and multilineage differentiation. Stem Cells 2009;27: 1529-1537.

8 Tokuzawa Y, Kaiho E, Maruyama M, Takahashi K, Mitsui K, Maeda M, et al: Fbx 15 is a novel target of Oct $3 / 4$ but is dispensable for embryonic stem cell selfrenewal and mouse development. Mol Cell Biol 2003;23:2699-2708.

9 Papanayotou C, Collignon J: Activin/ Nodal signalling before implantation: setting the stage for embryo patterning. Philos Trans R Soc Lond B Biol Sci 2014, DOI: 10.1098/rstb.2013.0539.
10 Kuijk EW, van Tol LT, van de Velde H, Wubbolts R, Welling M, Geijsen N, et al: The roles of FGF and MAP kinase signaling in the segregation of the epiblast and hypoblast cell lineages in bovine and human embryos. Development 2012;139:871-882.

11 Denicol AC, Dobbs KB, McLean KM, Carambula SF, Loureiro B, Hansen PJ: Canonical WNT signaling regulates development of bovine embryos to the blastocyst stage. Sci Rep 2013;3:1266.

12 Nakamura T, Okamoto I, Sasaki K, Yabuta Y, Iwatani C, Tsuchiya H, et al: A developmental coordinate of pluripotency among mice, monkeys and humans. Nature 2016;537:57-62.

13 Sasaki K, Nakamura T, Okamoto I, Yabuta Y, Iwatani C, Tsuchiya H, et al: The germ cell fate of cynomolgus monkeys is specified in the nascent amnion. Dev Cell 2016;39:169-185.

14 Frankenberg SR: Different species choose their own paths to pluripotency. Dev Cell 2015;35:267-268.

15 Lawson KA, Hage WJ: Clonal analysis of the origin of primordial germ cells in the mouse. Ciba Found Symp 1994;182: 68-84, discussion 84-91.

16 McLaren A: Primordial germ cells in the mouse. Dev Biol 2003;262:1-15.

17 Saitou M, Barton SC, Surani MA: A molecular programme for the specification of germ cell fate in mice. Nature 2002; 418:293-300.

18 Gerovska D, Arauzo-Bravo MJ: Does mouse embryo primordial germ cell activation start before implantation as suggested by single-cell transcriptomics dynamics? Mol Hum Reprod 2016;22: 208-225.
19 Irie N, Weinberger L, Tang WW, Kobayashi T, Viukov S, Manor YS, et al: SOX17 is a critical specifier of human primordial germ cell fate. Cell 2015;160: 253-268.

20 Tang WW, Dietmann S, Irie N, Leitch HG, Floros VI, Bradshaw CR, et al: A unique gene regulatory network resets the human germline epigenome for development. Cell 2015;161:1453-1467.

21 Sugawa F, Arauzo-Bravo MJ, Yoon J, Kim KP, Aramaki S, Wu G, et al: Human primordial germ cell commitment in vitro associates with a unique PRDM14 expression profile. EMBO J 2015;34: 1009-1024.

22 Sasaki K, Yokobayashi S, Nakamura T, Okamoto I, Yabuta Y, Kurimoto K, et al: Robust in vitro induction of human germ cell fate from pluripotent stem cells. Cell Stem Cell 2015;17:178-194.

23 Gunesdogan U, Magnusdottir E, Surani MA: Primordial germ cell specification: a context-dependent cellular differentiation event [corrected]. Philos Trans R Soc Lond B Biol Sci 2014, DOI: 10.1098/ rstb.2013.0543.

24 Yamaji M, Seki Y, Kurimoto K, Yabuta Y, Yuasa M, Shigeta M, et al: Critical function of Prdm14 for the establishment of the germ cell lineage in mice. Nat Genet 2008;40:1016-1022.

25 Campolo F, Gori M, Favaro R, Nicolis S, Pellegrini M, Botti F, et al: Essential role of Sox 2 for the establishment and maintenance of the germ cell line. Stem Cells 2013;31:1408-1421.

26 Perrett RM, Turnpenny L, Eckert JJ, O'Shea M, Sonne SB, Cameron IT, et al: The early human germ cell lineage does not express SOX2 during in vivo development or upon in vitro culture. Biol Reprod 2008;78:852-858. 
27 Boyer LA, Lee TI, Cole MF, Johnstone SE, Levine SS, Zucker JP, et al: Core transcriptional regulatory circuitry in human embryonic stem cells. Cell 2005; 122:947-956.

28 Turnpenny L, Spalluto CM, Perrett RM, O'Shea M, Hanley KP, Cameron IT, et al: Evaluating human embryonic germ cells: concord and conflict as pluripotent stem cells. Stem Cells 2006;24:212-220.

29 Aeckerle N, Drummer C, Debowski K, Viebahn C, Behr R: Primordial germ cell development in the marmoset monkey as revealed by pluripotency factor expression: suggestion of a novel model of embryonic germ cell translocation. Mol Hum Reprod 2015;21:66-80.

30 Lin IY, Chiu FL, Yeang CH, Chen HF, Chuang CY, Yang SY, et al: Suppression of the SOX2 neural effector gene by PRDM1 promotes human germ cell fate in embryonic stem cells. Stem Cell Rep 2014;2:189-204.

31 Magnusdottir E, Surani MA: How to make a primordial germ cell. Development 2014;141:245-252.

32 Lawson KA, Dunn NR, Roelen BA, Zeinstra LM, Davis AM, Wright CV, et al: Bmp4 is required for the generation of primordial germ cells in the mouse embryo. Genes Dev 1999;13:424-436.

33 Skreb N, Solter D, Damjanov I: Developmental biology of the murine egg cylinder. Int J Dev Biol 1991;35:161-176.

34 De Felici M: Origin, migration, and proliferation of human primordial germ cells; in Coticchio G, Albertini DF, De Santis L (eds): Oogenesis. London, Springer, 2013, p 364.

35 Politzer G: Die Keimbahn des Menschen. Z Anat Entwicklungsgesch 1933; 100:331-361.

36 Witschi E: Migration of the germ cells of human embryo from the yolk sac to the primitive gonadal folds. Contrib Embryol 1948;32:67-97.

37 Kerr CL, Hill CM, Blumenthal PD, Gearhart JD: Expression of pluripotent stem cell markers in the human fetal testis. Stem Cells 2008;26:412-421.

38 Mamsen LS, Brochner CB, Byskov AG, Mollgard K: The migration and loss of human primordial germ stem cells from the hind gut epithelium towards the gonadal ridge. Int J Dev Biol 2012;56: 771-778.
39 Manku G, Culty M: Mammalian gonocyte and spermatogonia differentiation: recent advances and remaining challenges. Reproduction 2015;149:R139_ R157.

40 McKinnell C, Mitchell RT, Walker M, Morris K, Kelnar CJ, Wallace WH, et al: Effect of fetal or neonatal exposure to monobutyl phthalate (MBP) on testicular development and function in the marmoset. Hum Reprod 2009;24:22442254.

41 Yoshida S, Sukeno M, Nakagawa T, Ohbo K, Nagamatsu G, Suda T, et al: The first round of mouse spermatogenesis is a distinctive program that lacks the self-renewing spermatogonia stage. Development 2006;133:1495-1505.

42 Su S, Szarek M, Vooght A, Hutson J, Li R: Gonocyte transformation to spermatogonial stem cells occurs earlier in patients with undervirilisation syndromes. J Pediatr Surg 2014;49:323327.

43 Lin ZY, Hirano T, Shibata S, Seki NM, Kitajima R, Sedohara A, et al: Gene expression ontogeny of spermatogenesis in the marmoset uncovers primate characteristics during testicular development. Dev Biol 2015;400:43-58.

44 Aeckerle N, Eildermann K, Drummer C, Ehmcke J, Schweyer S, Lerchl A, et al: The pluripotency factor LIN28 in monkey and human testes: a marker for spermatogonial stem cells? Mol Hum Reprod 2012;18:477-488.

45 Eildermann K, Aeckerle N, Debowski K, Godmann M, Christiansen H, Heistermann M, et al: Developmental expression of the pluripotency factor sal-like protein 4 in the monkey, human and mouse testis: restriction to premeiotic germ cells. Cells Tissues Organs 2012; 196:206-220.

46 Kelnar CJ, McKinnell C, Walker M, Morris KD, Wallace WH, Saunders PT, et al: Testicular changes during infantile "quiescence" in the marmoset and their gonadotrophin dependence: a model for investigating susceptibility of the prepubertal human testis to cancer therapy? Hum Reprod 2002;17:1367-1378.

47 Hilscher B, Engemann A: Histological and morphometric studies on the kinetics of germ cells and immature Sertoli cells during human prespermatogenesis. Andrologia 1992;24:7-10.
48 Gueler B, Sonne SB, Zimmer J, Hilscher B, Hilscher W, Graem N, et al: AZFa protein DDX3Y is differentially expressed in human male germ cells during development and in testicular tumours: new evidence for phenotypic plasticity of germ cells. Hum Reprod 2012;27:1547-1555.

49 Vergouwen RP, Huiskamp R, Bas RJ, Roepers-Gajadien HL, Davids JA, de Rooij DG: Postnatal development of testicular cell populations in mice. J Reprod Fertil 1993;99:479-485.

50 Li LH, Donald JM, Golub MS: Review on testicular development, structure, function, and regulation in common marmoset. Birth Defects Res B Dev Reprod Toxicol 2005;74:450-569.

51 Wahab F, Drummer C, Schlatt S, Behr R Dynamic regulation of hypothalamic DMXL2, KISS1, and RFRP expression during postnatal development in nonhuman primates. Mol Neurobiol 2017, DOI: 10.1007/s12035-016-0329-x.

52 Wahab F, Shahab M, Behr R: The involvement of gonadotropin inhibitory hormone and kisspeptin in the metabolic regulation of reproduction. J Endocrinol 2015;225:R49-R66.

53 Larke A, Crews DE: Parental investment, late reproduction, and increased reserve capacity are associated with longevity in humans. J Physiol Anthropol 2006;25:119-131.

54 De Rooij DG: Proliferation and differentiation of spermatogonial stem cells. Reproduction 2001;121:347-354.

55 Hermann BP, Sukhwani M, Hansel MC, Orwig KE: Spermatogonial stem cells in higher primates: are there differences from those in rodents? Reproduction 2010;139:479-493.

56 Hobbs RM, Fagoonee S, Papa A, Webster K, Altruda F, Nishinakamura R, et al: Functional antagonism between Sall 4 and Plzf defines germline progenitors. Cell Stem Cell 2012;10:284-298.

57 Zheng K, Wu X, Kaestner KH, Wang PJ The pluripotency factor LIN28 marks undifferentiated spermatogonia in mouse. BMC Dev Biol 2009;9:38.

58 Ehmcke J, Schlatt S: A revised model for spermatogonial expansion in man: lessons from non-human primates. Reproduction 2006;132:673-680. 
59 Hara K, Nakagawa T, Enomoto H, Suzuki M, Yamamoto M, Simons BD, et al: Mouse spermatogenic stem cells continually interconvert between equipotent singly isolated and syncytial states. Cell Stem Cell 2014;14:658-672.

60 Tsialikas J, Romer-Seibert J: LIN28: roles and regulation in development and beyond. Development 2015;142:23972404.

61 Gradwohl G, Dierich A, LeMeur M, Guillemot F: neurogenin 3 is required for the development of the four endocrine cell lineages of the pancreas. Proc Natl Acad Sci USA 2000;97:1607-1611.

62 Wistuba J, Schrod A, Greve B, Hodges JK, Aslam H, Weinbauer GF, et al: Organization of seminiferous epithelium in primates: relationship to spermatogenic efficiency, phylogeny, and mating system. Biol Reprod 2003;69:582-591.

63 Ehmcke J, Wistuba J, Schlatt S: Spermatogonial stem cells: questions, models and perspectives. Hum Reprod Update 2006;12:275-282.

64 Millar MR, Sharpe RM, Weinbauer GF, Fraser HM, Saunders PT: Marmoset spermatogenesis: organizational similarities to the human. Int J Androl 2000; 23:266-277.

65 Herndon JG, Bein ML, Nordmeyer DL, Turner JJ: Seasonal testicular function in male rhesus monkeys. Horm Behav 1996;30:266-271.

66 Nagano M, Avarbock MR, Leonida EB, Brinster CJ, Brinster RL: Culture of mouse spermatogonial stem cells. Tissue Cell 1998;30:389-397.

67 Kanatsu-Shinohara M, Ikawa M, Takehashi M, Ogonuki N, Miki H, Inoue K, et al: Production of knockout mice by random or targeted mutagenesis in spermatogonial stem cells. Proc Natl Acad Sci USA 2006; 103:8018-8023.

68 Guan K, Nayernia K, Maier LS, Wagner S, Dressel R, Lee JH, et al: Pluripotency of spermatogonial stem cells from adult mouse testis. Nature 2006;440:1199_ 1203.

69 Stukenborg JB, Wistuba J, Luetjens CM, Elhija MA, Huleihel M, Lunenfeld E, et al: Coculture of spermatogonia with somatic cells in a novel three-dimensional soft-agar-culture-system. J Androl 2008;29:312-329.
70 Reda A, Hou M, Landreh L, Kjartansdottir KR, Svechnikov K, Soder O, et al: In vitro spermatogenesis - optimal culture conditions for testicular cell survival, germ cell differentiation, and steroidogenesis in rats. Front Endocrinol (Lausanne) 2014;5:21.

71 Stukenborg JB, Schlatt S, Simoni M, Yeung CH, Elhija MA, Luetjens CM, et al: New horizons for in vitro spermatogenesis? An update on novel three-dimensional culture systems as tools for meiotic and post-meiotic differentiation of testicular germ cells. Mol Hum Reprod 2009;15:521-529.

72 Reda A, Hou M, Winton TR, Chapin RE, Soder O, Stukenborg JB: In vitro differentiation of rat spermatogonia into round spermatids in tissue culture. Molr Hum Reprod 2016;22:601-612.

73 Sato T, Katagiri K, Gohbara A, Inoue K, Ogonuki N, Ogura A, et al: In vitro production of functional sperm in cultured neonatal mouse testes. Nature 2011;471: 504-507.

74 Sato T, Katagiri K, Yokonishi T, Kubota $\mathrm{Y}$, Inoue $\mathrm{K}$, Ogonuki N, et al: In vitro production of fertile sperm from murine spermatogonial stem cell lines. Nat Commun 2011;2:472.

75 Kossack N, Terwort N, Wistuba J, Ehmcke J, Schlatt S, Scholer H, et al: A combined approach facilitates the reliable detection of human spermatogonia in vitro. Hum Reprod 2013;28:3012-3025.

76 Zheng Y, Thomas A, Schmidt CM, Dann CT: Quantitative detection of human spermatogonia for optimization of spermatogonial stem cell culture. Hum Reprod 2014;29:2497-2511.

77 Eildermann K, Gromoll J, Behr R: Misleading and reliable markers to differentiate between primate testis-derived multipotent stromal cells and spermatogonia in culture. Hum Reprod 2012;27: 1754-1767.

78 Langenstroth D, Kossack N, Westernstroer B, Wistuba J, Behr R, Gromoll J, et al: Separation of somatic and germ cells is required to establish primate spermatogonial cultures. Hum Reprod 2014;29:2018-2031.

79 Sadri-Ardekani H, Mizrak SC, van Daalen SK, Korver CM, Roepers-Gajadien HL, Koruji M, et al: Propagation of human spermatogonial stem cells in vitro. JAMA 2009;302:2127-2134.
80 Nickkholgh B, Mizrak SC, van Daalen SK, Korver CM, Sadri-Ardekani H, Repping S, et al: Genetic and epigenetic stability of human spermatogonial stem cells during long-term culture. Fertil Steril 2014;102:1700-1707.e1.

81 Smith JF, Yango P, Altman E, Choudhry S, Poelzl A, Zamah AM, et al: Testicular niche required for human spermatogonial stem cell expansion. Stem Cells Transl Med 2014;3:1043-1054.

82 Conrad S, Azizi H, Hatami M, Kubista M, Bonin M, Hennenlotter J, et al: Differential gene expression profiling of enriched human spermatogonia after short- and long-term culture. Biomed Res Int 2014;2014:138350.

83 Yang S, Ping P, Ma M, Li P, Tian R, Yang H, et al: Generation of haploid spermatids with fertilization and development capacity from human spermatogonial stem cells of cryptorchid patients. Stem Cell Reports 2014;3:663-675.

84 Jahnukainen K, Mitchell RT, Stukenborg JB: Testicular function and fertility preservation after treatment for haematological cancer. Curr Opin Endocrinol Diabetes Obes 2015;22:217-223.

85 Hermann BP, Sukhwani M, Winkler F, Pascarella JN, Peters KA, Sheng Y, et al: Spermatogonial stem cell transplantation into rhesus testes regenerates spermatogenesis producing functional sperm. Cell Stem Cell 2012;11:715-726.

86 Weinberger L, Ayyash M, Novershtern N, Hanna JH: Dynamic stem cell states: naive to primed pluripotency in rodents and humans. Nat Rev Mol Cell Biol 2016;17:155-169.

87 Massart A, Lissens W, Tournaye H, Stouffs K: Genetic causes of spermatogenic failure. Asian J Androl 2012;14: 40-48.

88 Yatsenko AN, Iwamori N, Iwamori T, Matzuk MM: The power of mouse genetics to study spermatogenesis. J Androl 2010;31:34-44.

89 Yatsenko AN, Georgiadis AP, Ropke A, Berman AJ, Jaffe T, Olszewska M, et al: X-linked TEX11 mutations, meiotic arrest, and azoospermia in infertile men. New Engl J Med 2015;372:2097-2107.

90 Archambeault DR, Matzuk MM: Disrupting the male germ line to find infertility and contraception targets. Ann Endocrinol 2014;75:101-108.

91 Zhang YE, Long M: New genes contribute to genetic and phenotypic novelties in human evolution. Curr Opin Genet Dev 2014;29C:90-96. 
92 Carelli FN, Hayakawa T, Go Y, Imai H, Warnefors M, Kaessmann H: The life history of retrocopies illuminates the evolution of new mammalian genes. Genome Res 2016;26:301-314.

93 Gromoll J, Weinbauer GF, Skaletsky H, Schlatt S, Rocchietti-March M, Page DC, et al: The Old World monkey DAZ (deleted in azoospermia) gene yields insights into the evolution of the DAZ gene cluster on the human Y chromosome. Hum Mol Genet 1999;8:20172024.

94 Kuroda-Kawaguchi T, Skaletsky H, Brown LG, Minx PJ, Cordum HS, Waterston $\mathrm{RH}$, et al: The AZFc region of the $\mathrm{Y}$ chromosome features massive palindromes and uniform recurrent deletions in infertile men. Nat Genet 2001;29: 279-286.

95 Rozen SG, Marszalek JD, Irenze K, Skaletsky H, Brown LG, Oates RD, et al: AZFc deletions and spermatogenic failure: a population-based survey of 20,000 Y chromosomes. Am J Hum Genet 2012; 91:890-896.

96 Kaessmann H: Origins, evolution, and phenotypic impact of new genes. Genome Res 2010;20:1313-1326.

97 Xie C, Zhang YE, Chen JY, Liu CJ, Zhou WZ, Li Y, et al: Hominoid-specific de novo protein-coding genes originating from long non-coding RNAs. PLoS Genet 2012;8:e1002942.
98 Necsulea A, Kaessmann H: Evolutionary dynamics of coding and non-coding transcriptomes. Nat Rev Genet 2014;15:734-748.

99 Brawand D, Soumillon M, Necsulea A, Julien P, Csardi G, Harrigan P, et al: The evolution of gene expression levels in mammalian organs. Nature 2011; 478:343-348.

100 Merkin J, Russell C, Chen P, Burge CB: Evolutionary dynamics of gene and isoform regulation in Mammalian tissues. Science 2012;338:1593-1599.

101 Ade C, Roy-Engel AM, Deininger PL: Alu elements: an intrinsic source of human genome instability. Curr Opin Virol 2013;3:639-645.

102 Deininger P: Alu elements: know the SINEs. Genome Biol 2011;12:236.

103 Callinan PA, Batzer MA: Retrotransposable elements and human disease. Genome Dyn 2006;1:104-115.

104 Xing J, Wang H, Belancio VP, Cordaux R, Deininger PL, Batzer MA: Emergence of primate genes by retrotransposon-mediated sequence transduction. Proc Natl Acad Sci USA 2006;103: 17608-17613.

105 Elbarbary RA, Lucas BA, Maquat LE: Retrotransposons as regulators of gene expression. Science 2016;351:aac7247.

106 Denli AM, Narvaiza I, Kerman BE, Pena M, Benner C, Marchetto MC, et al: Primate-specific ORF0 contributes to retrotransposon-mediated diversity. Cell 2015;163:583-593.
107 Steger K: Transcriptional and translational regulation of gene expression in haploid spermatids. Anat Embryol 1999;199:471-487.

108 Soumillon M, Necsulea A, Weier M, Brawand D, Zhang X, Gu H, et al: Cellular source and mechanisms of high transcriptome complexity in the mammalian testis. Cell Rep 2013;3:21792190.

109 Joseph SB, Kirkpatrick M: Haploid selection in animals. Trends Ecol Evol 2004;19:592-597.

110 Jodar M, Sendler E, Moskovtsev SI, Librach CL, Goodrich R, Swanson S, et al: Absence of sperm RNA elements correlates with idiopathic male infertility. Sci Transl Med 2015;7:295re6.

111 Rogenhofer N, Dansranjavin T, Schorsch M, Spiess A, Wang H, von Schonfeldt $V$, et al: The sperm protamine mRNA ratio as a clinical parameter to estimate the fertilizing potential of men taking part in an ART programme. Hum Reprod 2013;28:969978.

112 Bunick D, Balhorn R, Stanker LH, Hecht NB: Expression of the rat protamine 2 gene is suppressed at the level of transcription and translation. Exp Cell Res 1990;188:147-152.

113 Hecht N, Behr R, Hild A, Bergmann M, Weidner W, Steger K: The common marmoset (Callithrix jacchus) as a model for histone and protamine expression during human spermatogenesis. Hum Reprod 2009;24:536-545. 